\title{
Economic Value Approach to Intermittent Power Generation in the Nordic Power Markets
}

\author{
Maria Kopsakangas-Savolainen ${ }^{1,2,3} \&$ Rauli Svento $^{3}$ \\ ${ }^{1}$ Finnish Environment Institute, Helsinki, Finland \\ 2 Thule Institute, University of Oulu, Oulu, Finland \\ ${ }^{3}$ Department of Economics and Martti Ahtisaari, Institute of Global Business and Economics, University of \\ Oulu, Oulu, Finland
}

Correspondence: Maria Kopsakangas-Savolainen, Finnish Environment Institute, Helsinki, Finland. Tel: 358-40-187-4284. E-mail: maria.kopsakangas@oulu.fi

\author{
Received: October 10, 2013 Accepted: November 2, 2013 Online Published: November 15, 2013 \\ doi:10.5539/eer.v3n2p139 URL: http://dx.doi.org/10.5539/eer.v3n2p139
}

\begin{abstract}
The key elements in solving the increasing problems of power generation are to develop a sustainable and efficient production system and to utilize consumer management and demand response in a clearly stronger way than have been recently done. A significant part of the renewable energy (wind and solar) differs from most conventional (fossil fuel and nuclear) generating technologies such that they produce electricity intermittently and are not dispatchable. If traditional levelized cost approach is used it gives inappropriate and misleading results. In this paper we utilize a long-run oriented Real-Time Price based model to analyze the economic value of intermittent electricity generation in the Nordic power markets. Using this type of model it is possible to simultaneously take into account the increasing role of demand response and the specific characteristics of intermittent technology. We study the impacts of a change in production profile and increase in the share of intermittent generation to the market prices, equilibrium of other capacities, production costs, profits and $\mathrm{CO}_{2}$ emissions. Our approach which uses hourly output profiles and associated market value of electricity, gives plausible economic values for electricity.
\end{abstract}

Keywords: intermittent generation, efficient production, economic value, emission reductions

\section{Introduction}

Energy and electricity have become key elements and drivers in the modern world. In our networked economies with digital products and processes and device driven consumption, stabile, riskless and justly priced electricity supply is the current day basement upon which everything else more or less builds on. At the same time the use of many primary energy sources can be connected with greenhouse gas emissions and global warming. This basement has also gone through heavy structural changes and even bigger changes can be seen in the future. The key elements in solving the increasing problems of power generation are to develop a sustainable and efficient production system and to utilize consumer management and demand response in a clearly stronger way than have been recently done (Kopsakangas-Savolainen \& Svento, 2012a, 2012b; Joskow, 2012).

In developing a sustainable power production structure the role of renewable energy is increasing. The European Union (EU) has adopted specific targets for both $\mathrm{CO}_{2}$ reductions and electricity production from renewable sources, by the year 2020. The share of the renewable energy is going to be increased up to $20 \%$ of the total energy consumed (EC, 2007). National targets differ clearly and member states can decide what kind operations and support mechanism they are using in order to reach these national targets.

A significant part of the renewable energy (wind and solar) differs from most conventional (fossil fuel and nuclear) generating technologies such that they are not dispatchable. Typically we have been used to situation where the system operator has scheduled the production to meet demand by dispatching the generators with the lowest marginal generation cost first and then moving up the dispatch curve. Generally speaking this means that generators are dispatched when the wholesale market price for power exceeds short-run marginal cost of generation (Joskow, 2011). The non-dispatchable, so called "intermittent technologies" (wind and solar), produce electricity intermittently and are driven more by weather conditions (such as wind speed and direction, cloud 
cover etc.) than by economic factors.

In this paper we utilize a long-run oriented Real-Time Price (RTP) based model (Borentstein, 2005; Borenstein \& Holland, 2005; Kopsakangas-Savolainen \& Svento, 2012b, 2013) to analyze the economic value of intermittent electricity generation in the Nordic power market framework. Even though the model is fit to the Nordic power market framework the results can be generalized also to other markets with similar structures (Note 1). By using simulation techniques we study the impacts of the increase in the share of intermittent generation to the market prices, equilibrium of other capacities, production costs, profits and $\mathrm{CO}_{2}$ emissions. We show that as traditional levelized cost comparisons fail to take into account the fact that the value of electricity supplied varies widely over the year, our approach which uses hourly output profiles and associated market value of electricity, gives plausible economic values for electricity. We also point out that it is especially important to recognize that intermittent generating technologies can have very different hourly production profiles (and thus economic value profiles) depending on the location and wind/solar characteristics of the area analyzed. Consequently economic value of intermittent power can be very different in different countries or areas and this should be recognized when comparing the investment costs (and other consequences) of different technologies.

The paper is organized as follows. In section 2 we give background information on earlier literature related to intermittent generation. Section 3 presents the main characteristics of the Nordic power markets and gives summarization of the data. In section 4 the simulation model and iteration procedure are described. In section 5 we present and discuss the simulation results. Section 6 gives conclusions.

\section{Earlier Literature}

Literature on the role of intermittent technologies in the energy system has grown fast in recent years. Vast majority of this literature is still technology oriented and relates to questions of stability of the system. Traditional technologies are dispatchable in the sense that they can be integrated into the system whenever demand it necessitates. This is not the case with intermittent technologies which can be integrated into the dispatch curve when the wind blows or sun shines. The basic technical issues related to costs and reliability standards with large volumes of intermittent energy capacity have been summarized in many reports by e.g. The North-American Electric Reliability Corporation (NERC), US Department of Energy (USDOE), New York ISO (NYISO) and Mount et al. (2011). NERC (2007) uses two concepts to evaluate the reliability of the electric supply system:

(1). Adequacy. The ability of the electric system to supply the aggregate electrical demand and energy requirements of customers at all times, taking into account scheduled and reasonably expected unscheduled outages of system elements.

(2). Operating reliability. The ability of electric system to withstand sudden disturbances such as electric short circuits or unanticipated failure of system elements.

Adequacy is in most cases identified with simple measures like Loss of Load Expectation (LOLE). Using this measure adequacy can be said to be guaranteed if the past investments in the capacity and networks of the system have been such that LOLE is to to be met only in one day in ten years. Optimizing techniques where the objective function minimizes the total expected costs for a base case and a specified set of credible contingencies have also been developed in order to endogenize the optimal dispatch and nodal prices (Chen et al., 2005).

Game theoretic methods have also been widely used for analyzing the role of intermittent technologies in the energy system (Saad et al., 2012; Saad et al., 2011; Li et al., 2011). In these papers co-operational game theory is used in order to model intermittent and distributed energy sources as core parts of the electricity system. The approach is still technical in the sense that the objective of the game is defined somehow related to operating reliability or technical efficiency of the system. Either transfer losses are minimized or system supply reliability maximized.

Chalkiadakis et al. (2011) propose that small scale producers coalesce together to form a co-operative virtual power plant (CVPP) that can profitably be integrated into the grid. They incorporate ideas from mechanism design and co-operative game theory and put forward an energy pricing mechanism to be employed by the grid. The mechanism can be seen as an efficient alternative to feed-in tariffs, and so promotes the incorporation of distributed small scale producers in the grid. It has also other desirable properties. It guarantees that CVPPs have the incentive to truthfully report to the grid accurate estimates of their electricity production, and it promotes CVPP efficiency and reliability encouraging larger rather than smaller CVPPs. Further, individual producers are rewarded for increased production, while the grid maintains the ability to decide the flexibility of the mechanism and its degree of independence from market fluctuations. Chalkiadakis et al. (2011) also propose a payment 
scheme to allocate payments within the CVPP. This scheme guarantees payments to its members such that no subset of them has a financial incentive to break away from the CVPP.

Another line of research parts from the technical approaches by emphasizing economic questions. It has for instance been argued (Mount et al., 2011) that the adequacy measure is too narrow when large amounts of intermittent technologies are integrated into the system. Mount et al. argue that a new criterion which they call "Financial Adequacy" should be treated as a standard measure to evaluate the desired changes to system capacity Financial Adequacy relates to missing money coming from non-profitableness of those technologies that cannot be used with high peak hours. These are the intermittent technologies. This approach opens the question of the role of the system structure in defining the economic value of intermittent capacities and many economists have already grabbed this challenge.

Joskow (2011) shows how structural effects are a key driver when calculating the economic value of intermittent technologies. The traditional way to compare investment costs among different technologies is based on determining the "levelized cost" per MWh supplied. This means that we measure the real total life-cycle costs per MWh by supplier using a specific technology. Joskow points out that this method is inappropriate and misleading when we compare intermittent generating technologies with dispatchable generating technologies. Comparisons which use levelized costs are misleading since they fail to take into account the differences in production profiles among technologies. Differences in production profiles cause large variations in market value of the produced electricity. Differences in production profiles and the associated variations in the market value of electricity at the times it is supplied must be integrated with the expected levelized life-cycle costs to provide meaningful economic comparisons between them.

Lamont (2008) develops a theoretical framework to find the expression for the marginal value of intermittent technology as a function of the average system marginal cost, the capacity factor of the generator, and the covariance between the generator's hourly production and the hourly system marginal cost. Using this developed expression it is shown how large-scale intermittent generation tends to reduce the optimal capacity and production of baseload generators and increase the capacity and production of intermittent generators, although the result depends heavily on the pattern of production from the intermittent generators. These results are along the same lines than those that Joskow (2011) reaches with his extended value calculations.

Green and Vasilakos (2010) evaluate the impacts of intermittent wind generation on hourly equilibrium prices and output in the UK electricity market. They use data on expected wind generation capacities in different on-shore and off-shore locations for 2020. Their basic finding is that the volatility of prices increases, and significant year-to-year variation in generator's profits shall emerge. High wind speeds lead to lower prices, but annual revenues for British wind generators are almost as great as for baseload generators.

\section{Description of Nordic Power Market and the Data}

\subsection{Nordic Power Market}

The Nordic power market was the first international power market and it consists of four Nordic countries: Sweden, Finland, Norway and Denmark (Note 2). These countries run a common power exchange, the Nord Pool, where market participants can buy and sell electricity. The common power market was mainly motivated by efficiency reasons. The mix of production technologies in the Nordic Power market is quite large and it has been argued that it would improve the efficiency of production if market participants could trade between countries. The main part of the production in Finland and Denmark is based on thermal generation, whereas Norway is a very hydro-intensive country. In Sweden the electricity production is mainly based on hydro and nuclear power.

In the Nordic power market the wholesale trade of electricity is organized through Nord Pool power exchange. It is owned by national transmission system operators. The power exchange operates such that market participants make their quantity-price bids one day in advance to the hourly market. The resulting market clearing price for each hour is called the system price. Even though Nord Pool is a voluntary market more than $70 \%$ of the total consumption of electricity was traded through it in 2011. The aggregate demand for electricity in Nordic countries has been quite stable from year to year and the increase has been mainly due to economic growth. Some yearly variations happen along with variation in temperature. Price elasticity of demand has typically been very low because the price that final customers face is typically fixed for some period of time and prices do not follow the pattern of wholesale prices in the short run.

The transmission grid of the Nordic power market is operated by the national transmission operators. If the transmission across borders is not congested there is only one system price. In our simulations below we assume 
that the Nordic power market always forms only one price area (see e.g. Nordpool webpages for the discussion of bottlenecks). One price area is also actual target in Nordic Power markets in where the idea is to produce electricity always where it is most cost-efficient. Consequently, whenever there is only one price area, the location of production does not impact on the outcome of the market (e.g. on the system price).

Total net electricity production in the Nordic market was 378,6 TWh in 2011 (Eurelectric, 2012). Of that total, $80,3 \mathrm{TWh}$ was based on nuclear power, 200,2 TWh on hydropower, 55,2 TWh by using conventional thermal power plants and 35,7 TWh was based on other renewables. The installed wind power capacities in 2011 were the following: Sweden 2899 MW, Norway 515 MW, Denmark 3949 MW and Finland 226 MW (Eurelectric, 2012). The amount produced by hydropower can vary somewhat from year to year depending on precipitation. There are five nuclear power plants currently operating in Nordic countries. Three of them (10 reactors) are located in Sweden whereas two of them (4 reactors) are located in Finland. The peak technology includes oil fired condensing power plants as well as gas turbines. In our simulations below we divide our technologies into five representative technology groups based on the main characteristics of the Nordic Power market.

In Nordic power markets is operating under European Commission's internal emission trading. The emissions trading scheme is meant to operate so that the emissions of the companies under the scheme keep the pre-defined total emissions quantity within the limits. Power producers can buy permits from the emission permit markets. This increases the costs of technologies under emission trade.

\subsection{Data}

For the simulations we need data for the load profile and cost information of the different production technologies. The production specific cost data is presented in Table 1. The variable costs of midmerit and peaker units are determined with emission trade. Assumed emission price is $13 € / \mathrm{tCO}_{2}$ which is close to the real average emission price of years 2010-2011. Of course the actual mixture of production technologies is more diversified but for the purpose of this study somewhat less diversified production structure is sufficient.

Table 1. Capacity and generation costs

\begin{tabular}{ccccc}
\hline Generation type & $\begin{array}{c}\text { Specific investment } \\
\text { cost }(€ / \mathrm{kW})\end{array}$ & $\begin{array}{c}\text { Economic lifetime } \\
\text { (a) }\end{array}$ & $\begin{array}{c}\text { Annual Capital } \\
\text { Costs } € / \mathrm{MW}\end{array}$ & $\begin{array}{c}\text { Variable costs } \\
€ / \mathrm{MWh}\end{array}$ \\
\hline Wind power & 1300 & 25 & 92238 & 11 \\
Hydro power & 2000 & 75 & 102643 & 4 \\
Nuclear power & 3750 & 40 & 218543 & 23 \\
(baseload) & & & & \\
Midmerit power & 1370 & 25 & 99333 & 51 \\
Peaker power & 700 & 25 & 49667 & 87 \\
\hline
\end{tabular}

As noted above a major part of electricity production in the Nordic power market is based on hydro power. By nature the hydro power differs from most other technologies because of very low variable costs and its dependence on the precipitation of the year. It cannot be clearly identified as belonging to any of the groups: baseload, midmerit or peaker capacity. Part of it can be used as baseload capacity and part as balancing power. The cost of hydro power production of course depends on the type of the power plant and on other environmental factors. The annual capital cost of each technology is calculated by assuming $5 \%$ interest rate and by using a standard annuity formula. It is important to use annual capital cost since in the simulation model the demand is determined by the annual hourly load duration curve. Thus, we also need costs determined on a yearly basis. For hydro power we assume that investment costs are $2000 €$ per installed $\mathrm{kW}$ and that economic lifetime of that capacity is 75 years. Using an interest rate of $5 \%$ and the standard annuity formula we end up with the $102643 €$ capital cost per year. Variable costs include fuel costs, operation and maintenance costs, and the impact of emission permits' price on the variable costs. In the case of hydro power variable costs are basically equal to maintenance costs because fuel costs are equal to zero. It is notable that in the simulations we are assuming that the average utilization rate of the hydro power capacity is slightly below $50 \%$.

In simulations nuclear power production is assumed to be baseload production. As a specific investment cost of nuclear power we have used $3750 € / \mathrm{kW}$. This is clearly higher figure than suggested by Tarjanne and Kivistö (2008) and Vainio (2011) and it is based on recent evaluations of the final investment costs of the new nuclear power plant Olkiluoto 3 (Finland) which is under construction. If we assume a 40-year economic lifetime we end 
up with the annual capital costs of $218,543 € / \mathrm{MW}$.

The representative midmerit technology in our simulations is assumed to be coal and peat power plants. We have based our costs on the results of Tarjanne and Kivistö (2008) and Vainio (2011). The costs of the representative midmerit technology are partly (about $35 \%$ ) based on peat fired conventional thermal production and partly (about $65 \%$ ) on coal fired production. Specific investment costs of the midmerit technology are assumed to be about $1370 € / \mathrm{kW}$ which results in annual capital costs of 99333/MW over a 25 -year economic lifetime.

The capital and variable costs of peaker capacity vary depending on the technology used. Part of the peaker demand can be satisfied by oil fired condensing power plants, part by older power plants kept as reserve capacity, and the rest by the use of gas turbines. We assume that a representative peaker capacity investment cost is $700 €$ per installed $\mathrm{kW}$ which results annual capital costs of $49667 € / \mathrm{MW}$.

\section{Model and Simulation Algorithm}

The simulation model is based on the model developed by Borenstein and Holland (2005) and Borenstein (2005, 2007). Our application differs from their specification in the following features. Firstly, we apply the simulation model in the real Nordic Power market context and consequently the relevant features of the market have to be properly modeled. Secondly, we have capacity constrained technologies in the data base. These technologies are hydro and nuclear power (Kopsakangas-Savolainen \& Svento, 2012b, 2013). Thirdly, we include a volatile, non-dispatchable energy source (wind power) into our model.

Next we present the general logic behind the simulation model. Following Borenstein and Holland (2005) and Borenstein (2005) we assume a constant elasticity demand function. Since we do not estimate this demand function we have to calibrate it to correspond to the realized demand profiles. We have used the information on the load duration curve to do this. Our hourly load profile is based on hourly consumption data from NordPoolSpot 2011 and it is presented in Figure 1.

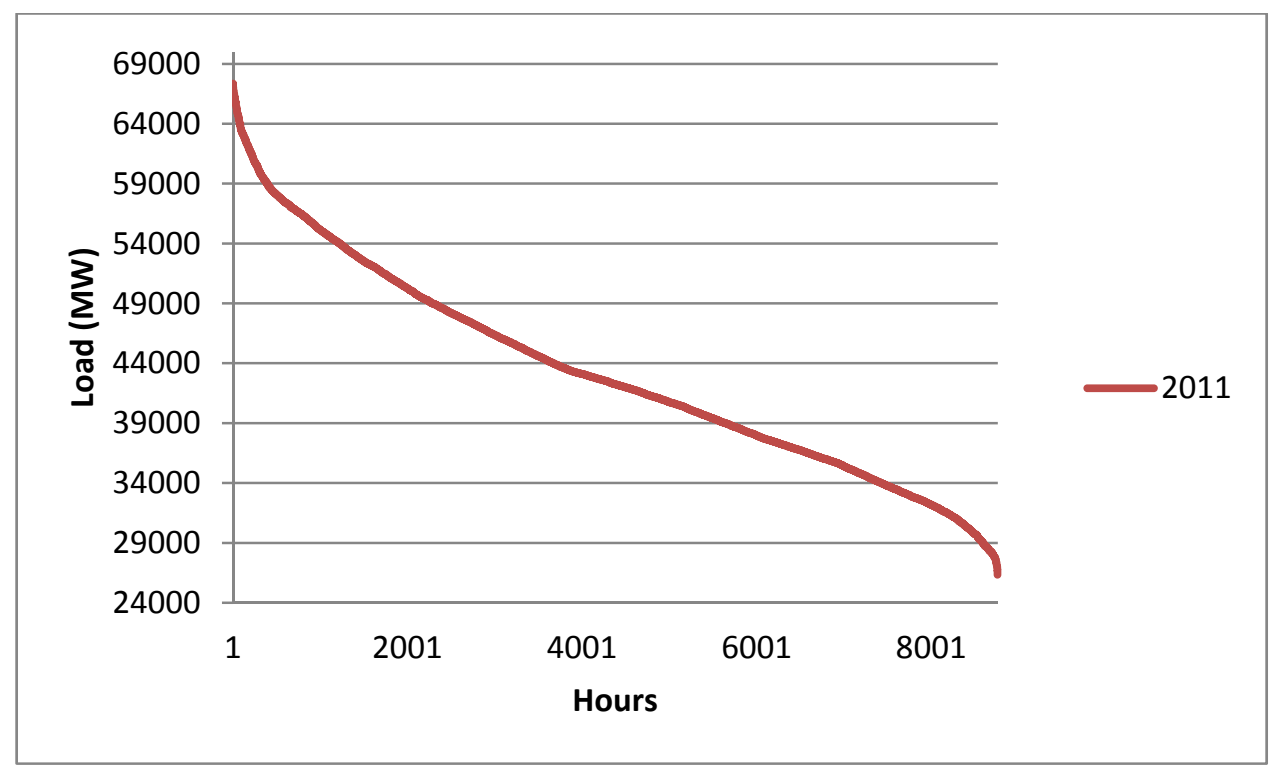

Figure 1. Load duration curve in Nordic Power markets 2011

Because intermittent generators cannot be dispatched, the chronological coincidence between generation and load is essential for analyzing the impact and value of intermittent generation. Intermittent generation can be included in a load duration curve analysis by treating intermittent generation as a "negative" load (Lamont, 2008). In practice this means that intermittent generation is subtracted hour by hour from load duration curve to obtain residual load for each hour. The resulting load duration curve is then constructed and analyzed to optimize the production and capacity of dispatchable generation. The procedure for this analysis is described next.

After identifying the residual load duration curve, the specification of the demand function has been done by calculating an "anchor point" $A_{h}$ for each hour of the year. In order to specify the anchor point we need to assume some constant price. We have used a price that would allow producers just to break even if they were charging that constant price from all customers. See Borenstein (2005) for a more detailed discussion of the role 
of this constant price. The anchor point can be determined as follows: $A_{h}=D_{h} / p^{\varepsilon}$, where $D$ is demand, $h$ is hour, $p$ is the constant price and $\varepsilon$ is the price elasticity for homogenous customers. Notable is that it is more important that we have accurate information of the shape of the hourly demand distribution than very specific information of the constant price. These anchor points are used to scale the demands to the load duration curve. Now let $\alpha$, $0<\alpha \leq 1$, be the share of customers on Real-Time Pricing, $p_{r}$ the retail price of electricity for the RTP customers and $p_{f}$ the flat rate price for non-RTP customers. The demand for electricity for hour $h$ can then be written:

$$
D_{h}\left(p_{r}, p_{f}\right)=\left[\alpha p_{r}^{\varepsilon}+(1-\alpha) p_{f}^{\varepsilon}\right] A_{h}, h=1, \ldots, 8760
$$

The simulation results related to the effect of RTP are based on varying $\alpha$ and $\varepsilon$ exogenously. We assume a competitive market structure in generation and in retail. We also assume that both retailers and generators will maximize profits and their profit functions can be written as follows:

$$
\begin{gathered}
\pi_{R}=\sum_{h=1}^{8760}\left[\left(p_{f}-w_{h}\right)(1-\alpha) D_{h}\left(p_{f}\right)+\left(p_{r}-w_{h}\right) \alpha D_{h}\left(p_{r}\right)\right] \\
\pi_{G}=\sum_{h=1}^{8760}\left(w_{h} D_{h}-c D_{h}\right)-r K
\end{gathered}
$$

where $R$ is retail sector, $G$ is generation sector, $w$ is wholesale price, $c$ is marginal generation costs and $r K$ is annual capital costs.

From Equations (1), (2) and (3) we can solve for short-run and long-run equilibrium of the generation and consumption systems. The logic of the simulation system is that the whole generation system is constructed MW by MW under the assumed economic principles (i.e. generators maximize profits according to Equation 3). After the construction of the whole generation system we turn to the retail sector and adjust the flat rate as long as the profits (see Equation 2) for the retail sector are equal to zero. Then we turn again to the generator sector and rebuild the whole system MW by MW with this new flat rate. These two rounds are repeated until we reach the long run equilibrium of the whole system.

\subsection{Equilibrium with one Technology}

To describe the simulation model and the solution procedure in a simple way assume first that only one capacity type (peaker capacity) without any scale effects is constructed and used. The short run supply curve with an assumed short-run capacity $K_{t o t}^{S R}$ is thus an inverted L-shaped curve as depicted in Figure 2.

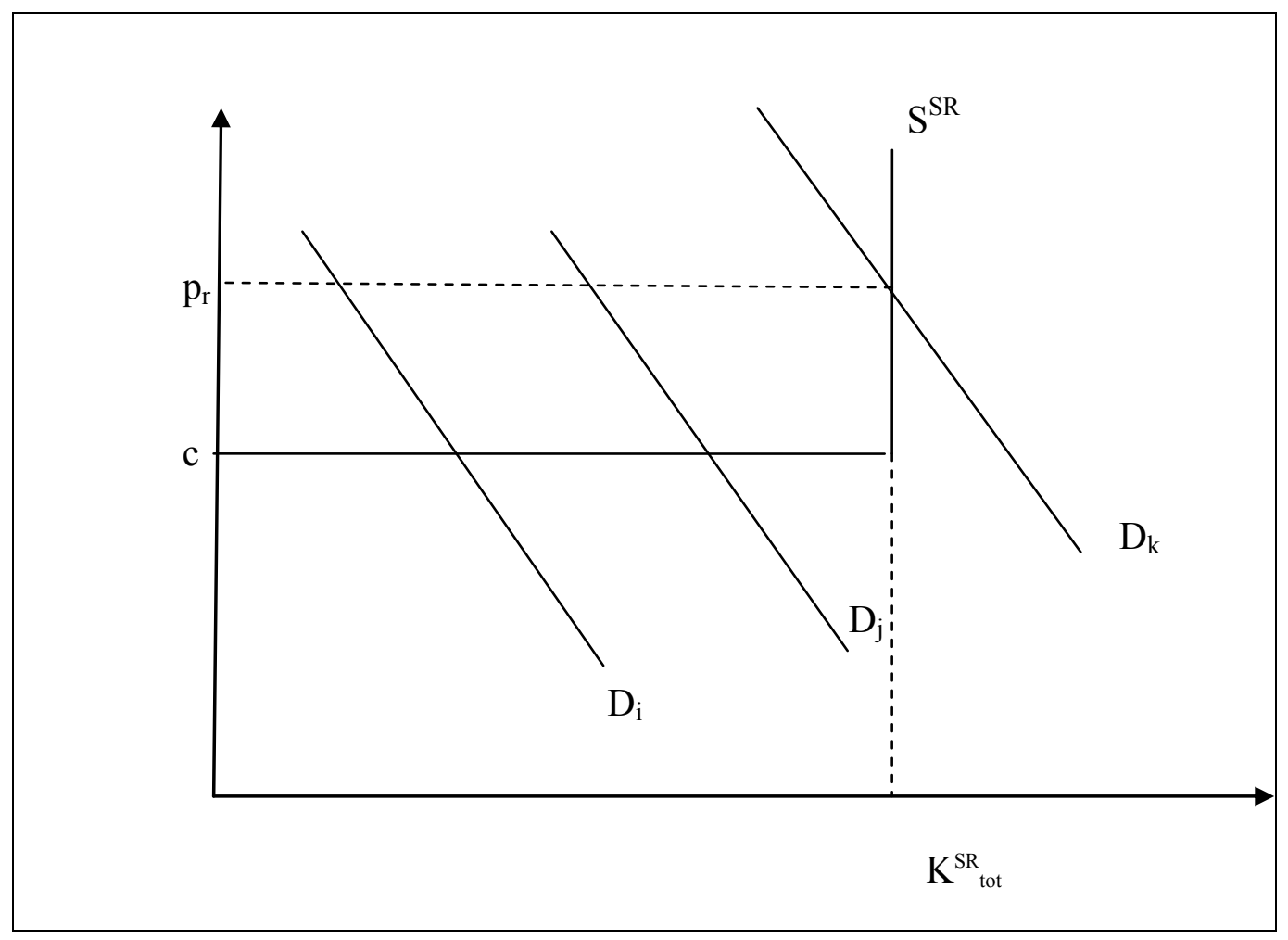

Figure 2 . The energy system with only one technology 
The short-run profits by hour are maximized by maximizing $\pi_{G}^{S R}=w_{h} D_{h}-c D_{h}$ with respect to given demand so that we have the known result: $w_{h}=c$. But this is true only when demand is not greater than the capacity limit, i.e. demands $D_{i}$ and $D_{j}$ in Figure 2. For those hours that demand exceeds the short-run capacity limit the real-time price must adjust to take care of market clearing. In equilibrium it has to be that demand equals to supply, i.e.:

$$
D_{k}=\left[\alpha p_{r}^{\varepsilon}+(1-\alpha) p_{f}\right] A_{h}=K_{t o t}^{S R}
$$

From where we can solve for the price $p_{r}$ :

$$
p_{r}=\left[\frac{K_{t o t}^{S R}-(1-\alpha) p_{f} A_{h}}{\alpha A_{h}}\right]^{-\varepsilon}
$$

So the wholesale pricing logic is as follows:

$$
\begin{aligned}
& w_{h}=c \text { when } D_{h} \leq K_{\text {tot }}^{S R} \\
& w_{h}=p_{r} \text { when } D_{h}>K_{\text {tot }}^{S R}
\end{aligned}
$$

Once we know the demand and wholesale price for each hour we can calculate profits for the generators. Because of competition we assume that capacity is built to the point where profits are equal to zero.

Next we solve for the flat rate. Competition forces the retail sector to zero profits also in the short-run. Abstracting from transmission and retail costs the real-time retail price must always be equal to the wholesale price. Should this not be the case there would be possibilities for undercutting the market price and this will go on as long as the retail price exceeds the wholesale price. So the zero profit condition for the retail sector reduces to:

$$
(1-\alpha) \sum_{h=1}^{H}\left(p_{f}-w_{h}\right) D_{h}\left(p_{f}\right)=0
$$

from which we can solve for pf :

$$
p_{f}=\sum_{h}^{H} w_{h} D_{h}\left(p_{f}\right) / \sum_{h}^{H} D_{h}\left(p_{f}\right)
$$

i.e. the zero profit short-run flat rate is a weighted average of the real-time wholesale price with weights being the relative quantities demanded by customers facing a flat retail price.

In the long run capacity is built to the point where both generators and retailers receive zero profits. As shown in Borenstein-Holland (2005) and Borenstein (2005) this kind of mechanism leads to a unique long-run equilibrium for the total generation capacity, $K_{t o t}^{L R}$.

\subsection{Equilibrium with a Technology Mix}

We can use the same kind of procedure as explained above to solve for the technology mix. Now however the total technology built consists of different types of technologies with different capital and variable costs. Because of competition we assume that capacity for those technologies which are not capacity constrained is built to the point where profits are equal to zero. Those technologies which are capacity constrained are built to the limit of the capacity constraint. In simulations we first analyze scenarios where peaker and midmerit technologies are optimized and then enlarge the analysis by running simulations where also nuclear power is optimized. Hydro power is assumed to be capacity constrained in every scenario. Wind power is non-dispatchable and its hourly values are subtracted from load duration curve before optimization of the residual curve.

In practice we first solve for short run total capacity $K_{\text {tot }}^{S R}$ by using peaker capacity only (just as described above). Then we start to replace peaker capacity with midmerit capacity. We construct the midmerit capacity to the point where the short run profits for midmerit capacity go to zero. If nuclear power is optimized, it is next constructed to replace midmerit capacities to the point where its short run profits are zero. Last we construct the capacity constrained technologies to the point where they reach the limit of their capacity.

After the short run technology mix for generation is solved we turn to the retail market and solve for the short run equilibrium for the retail market. Short run equilibrium for the retail market is reached when the retail sector produces zero profits (see Equation 8). From the zero profit condition we can solve for the new flat rate. With this new flat rate we start to construct again the whole generation technology mix. These two rounds are repeated until the equilibrium conditions for both sectors are simultaneously fulfilled. The long-run energy system 
equilibrium looks like the system in Figure 3.

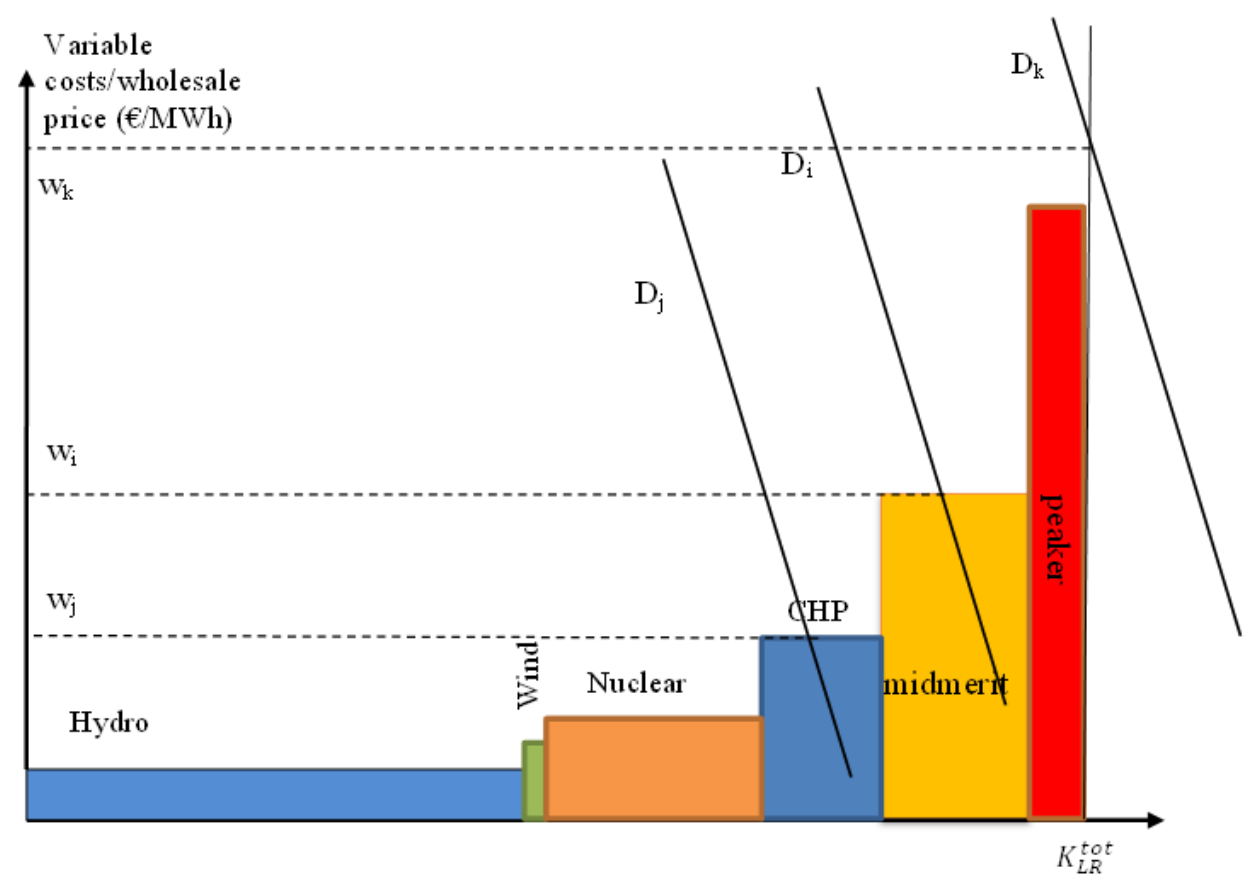

Figure 3. The long-run structure of the energy system

We have explained the basic model logic in reaching the long-run equilibrium with technology mix. In order to clarify the procedure reaching the long-run equilibrium with a complete set of technologies we next give summarization of the iteration procedure used.

Description of the algorithm:

a. Identify hourly based load duration curve. Identify hourly based production values and profile of intermittent generation. Subtract hour by hour intermittent generation from load duration curve to obtain residual load for each hour. Construct residual load duration curve. Specify demand function by using anchor point procedure described in the beginning of section 4 .

b. Make an assumption for $\alpha$ and $\varepsilon$. We have assumed that the share of RTP $(\alpha)$ is $33 \%$ and value of price elasticity $(\varepsilon)$ is $-0,05$ in every scenarios used in simulations (Note 3 , Note 4 ). Begin with an initial guess for the peaker technology capacity (Note 5). Then expand the quantity of peaker capacity, combine this short run supply function with the hourly demand and calculate short-run profits of the peak power generator. If profits are positive expand the quantity of peaker capacity again, recalculate the profits and so on. Continue the expansion of the capacity until expansion by one more unit causes profits to go negative for peak power generators. The resulting amount of capacity will typically be the equilibrium short run of total amount of all capacities $\left(K_{t o t}^{S R}\right)$. Note that in this equilibrium where only peak technology is used all profits to the generator are earned when the production is equal to the total amount of peak capacity. In hours where equilibrium quantity is less than $K_{\text {tot }}^{S R}$ price is equal to the marginal costs and profits resulting from these hours are equal to zero (see Figure 2).

c. Next, start substituting peaker capacity with midmerit capacity. The midmerit capacity will be lower on the supply function than the peaker capacity and thus it will be used in all hours before any of the peaker capacity. Follow the same procedure as with the peaker capacity, namely: expand midmerit capacity, combine short-run supply function with the demand and calculate profits of the midmerit units. If profits are positive continue expansion until expansion of the midmerit capacity by one more unit will cause profits of all mid-merit units to go negative. We refer to the total amount of midmerit capacity that still results in positive profits by $K_{\text {mid }}$.

d. Next begin substituting mid-merit capacity by the baseload capacity. Follow the same procedure as in stages a. and b. above. Note however, that in those scenarios where baseload capacity is constrained (Note 6) it should be taken into account. Expand the baseload capacity, combine the new short-run supply function 
to the demand and calculate profits. Again, if profits for nuclear power are positive continue expansion. Expand the capacity up to the point where expansion of capacity by one more unit will causes profits of all nuclear units to go negative or where the expanded capacity reaches the capacity constraint. Refer to the amount of baseload capacity by $K_{b}$.

e. Next take the capacity of hydro power generation into account at each hour of the year. Hydro power is first allocated evenly through hours such that total production during the year equals real production from the year where data is received. If then demand for an hour is lower than nuclear and hydropower production together, hydropower is reduced for those hours and reallocated to the later hours such that again yearly production equals real production (Note 7). Check that capacity constraint is not violated. Refer to the amount of hydro power capacity by $K_{H P}$.

f. Now one has determined the capacities of all types of technologies. One can determine short-run amounts of capacities using the following recursive logic:

$$
\begin{array}{cl}
\text { i. } & \text { Hydro power }=K_{H P}=K_{H P} \\
\text { ii. } & \text { Nuclear power }=K_{N P}=K_{b}-K_{H P} \\
\text { iii. } & \text { Midmerit power }=K_{M P}=K_{m i d}-K_{N P}-K_{H P} \\
\text { iv. } & \text { Peaker power }=K_{P P}=K_{\text {tot }}^{L R}-K_{M P}-K_{N P}-K_{H P}
\end{array}
$$

g. The final step of this procedure is to note that this equilibrium may not satisfy the retailer breakeven condition. So one must calculate the profits that the retailers earn from flat rate customers in this specific wholesale-producers equilibrium (note that profits for the retailer from RTP customers are always equal to zero). If the retailer profits from flat rate customers are negative, one adjusts the flat rate price up and if profits are positive one adjusts the flat rate price down. After this adjustment we need to re-simulate the capacity so we go back to point a. One has to continue this procedure until we reach equilibrium where retail markets also yield zero profits. This is the long-run unique competitive equilibrium energy system size and structure for a given set of available technologies, technology constraints, and share of customers on RTP and on flat rate.

\section{Results}

We have simulated the model under different assumptions about the production profile of intermittent generation, about the amount of intermittent generation and about the level of nuclear power. Scenarios A (see Table 2 below) are based on the assumption that nuclear power is constrained to the year 2011 level. In scenarios B we release this assumption and nuclear power is built up to the point where it receives zero profits. In both A and B type of scenarios we run simulations first by using 2011 level of intermittent production and then by assuming that the production is tripled from the 2011 level. The assumption of tripling the wind capacity in Nordic countries is very realistic if we consider the national targets by the year 2020 (Note 8).

We study the impact of the production profile of intermittent generation by assuming three different profiles in the simulations. First, we assume that the profile is similar as it was actually in year 2011 (this is referred as 2011 profile later on). Secondly, we assume that the profile is centered on the beginning of load duration curve, i.e. we organize the hourly wind volumes into a descending order and fit the resulting profile to the load duration curve (this is referred as "beginning" profile later on). Finally we assume that production is centered on the end of the load duration curve, i.e. we organize the hourly wind volumes into an ascending order and fit the resulting profile to the load duration curve (this is referred as "end" profile later on).

The capacity of hydropower is constrained at the level of 2011 in each scenario. Further, we assume that the total amount of electricity produced by using hydropower is the same in each scenario and it is assumed to be at the level of 2011 real production. However, the allocation of hydro power among different hours varies somewhat depending on the amount of wind power generation and nuclear power generation that can remove hydro production from the beginning of the load duration curve to the later hours. The procedure how this is done is reported more detailed in the description of the algorithm. 
Table 2. Description of scenarios. Scenarios vary between the assumption made on intermittent generation and nuclear power

\begin{tabular}{ccc}
\hline Scenario & Intermittent generation & Nuclear power \\
\hline Baseline scenario A & no & constrained (2011 level) \\
Scenario A1 & 2011 production profile & constrained (2011 level) \\
Scenario A2 & "beginning" production profile & constrained (2011 level) \\
Scenario A3 & "end" production profile & constrained (2011 level) \\
Baseline Scenario B & no & unconstrained \\
Scenario B1 & 2011 production profile & unconstrained \\
Scenario B2 & "beginning" production profile & unconstrained \\
Scenario B3 & "end" production profile & unconstrained \\
\hline
\end{tabular}

\subsection{Constrained Nuclear Power}

In the Table 3 we present the impact of different scenarios to the total energy consumed, capacities of different technologies, prices and hours when the full amount of production capacity is used. The levels of wind capacity are indicated by the numbers 1 (2011 level) and 2 (triple the level of 2011) after the double dot in each scenario, i.e. A1:1 refers to the scenario where nuclear power is constrained, the wind profile is 2011 profile and the wind power level is at the level of 2011 capacity.

As can be seen from Table 3 and from the Figures $4 a, 4 b$ and $4 c$ not only the amount of intermittent generation but also the allocation of this production among different hours has clear impacts on the need for dispatchable generation capacities. These impacts are strengthening as the level of wind capacity increases. If we use the 2011 load profile (scenarios A1) we see that as the wind power capacity increases the total dispatchable capacity decreases. Interesting is, however, that as the amount of midmerit capacity decreases the opposite happens to the peaker capacity. This is because of the location of wind production among different hours on the load duration curve.

Table 3. Production, capacities and prices with constrained nuclear power (Note 9)

\begin{tabular}{ccccccccc}
\hline Scenario & $\begin{array}{c}\text { Total } \\
\text { Annual } \\
\text { Energy } \\
\text { consumed } \\
\text { (TWh) }\end{array}$ & $\begin{array}{c}\text { Total } \\
\text { dispatchable } \\
\text { capacity, } \\
\text { MW }\end{array}$ & $\begin{array}{c}\text { Peaker } \\
\text { power } \\
\text { capacity, } \\
\text { MW }\end{array}$ & $\begin{array}{c}\text { Midmerit } \\
\text { power } \\
\text { capacity } \\
\text { MW }\end{array}$ & $\begin{array}{c}\text { Nuclear } \\
\text { power } \\
\text { capacity }\end{array}$ & $\begin{array}{c}\text { Flat rate } \\
€ / \text { MWh }\end{array}$ & $\begin{array}{c}\text { Peak } \\
\text { price } \\
€ / \text { MWh }\end{array}$ & $\begin{array}{c}\text { hours at } \\
\text { peak } \\
\text { quantity } \\
\text { (at } \\
8760)\end{array}$ \\
\hline $\begin{array}{c}\text { Baseline } \\
\text { Scenario } \\
\text { A }\end{array}$ & 374.08 & 62361 & 10080 & 20827 & 9446 & 65.86 & 3125.43 & 87 \\
$\begin{array}{c}\text { Scenario } \\
\text { A1:1 }\end{array}$ & 374.58 & 60809 & 10507 & 18748 & 9446 & 65.15 & 4804.92 & 83 \\
$\begin{array}{c}\text { Scenario } \\
\text { A2:1 }\end{array}$ & 374.92 & 62345 & 10595 & 19743 & 9446 & 64.31 & 3230.33 & 87 \\
$\begin{array}{c}\text { Scenario } \\
\text { A3:1 }\end{array}$ & 374.52 & 57197 & 7817 & 17910 & 9446 & 64.93 & 2301.68 & 99 \\
$\begin{array}{c}\text { Scenario } \\
\text { A1:2 }\end{array}$ & 375.99 & 58675 & 12066 & 14398 & 9446 & 62.31 & 5238.42 & 79 \\
$\begin{array}{c}\text { Scenario } \\
\text { A2:2 }\end{array}$ & 376.23 & 62293 & 11623 & 16279 & 9446 & 62.93 & 3444.16 & 82 \\
$\begin{array}{c}\text { Scenario } \\
\text { A3:2 }\end{array}$ & 375.49 & 47009 & 3412 & 12080 & 9446 & 62.511 & 1180.26 & 182 \\
\hline
\end{tabular}


From the Table 3 and Figures 4a, 4b, and 4c we also see that if wind power is allocated according to "beginning" profile on the load duration curve (scenarios A2), the required amount of total dispatchable capacity changes only slightly. This is because only very little wind is allocated to the peak demand hours which is the main determinant of the total required capacity. We see, however, that also in this scenario wind power replaces midmerit capacity but not peaker capacity, which in fact increases somewhat.

When we look at the results when the wind is allocated according to "end" profile on the load duration curve (scenarios A3) we see that the amount of total dispatchable capacity decreases substantially. Because wind is now located more on peak demand hours it replaces a significant amount of peak capacity but has only little impact to the amount of midmerit capacity. The changes in the capacity mixture indicate that the wind profile might have significant impact on the system costs and also to the emissions. The flat rate decreases somewhat as the amount of wind capacity increases. It seems, however, that the flat rate is not very sensitive to the production profile of intermittent generation. Peak price is clearly lowest under the scenario where intermittent generation is located more on the end of the load duration curve. This is because now the hours at peak quantity increase and the costs of peaker technology are recovered by more hours than under other profile scenarios.
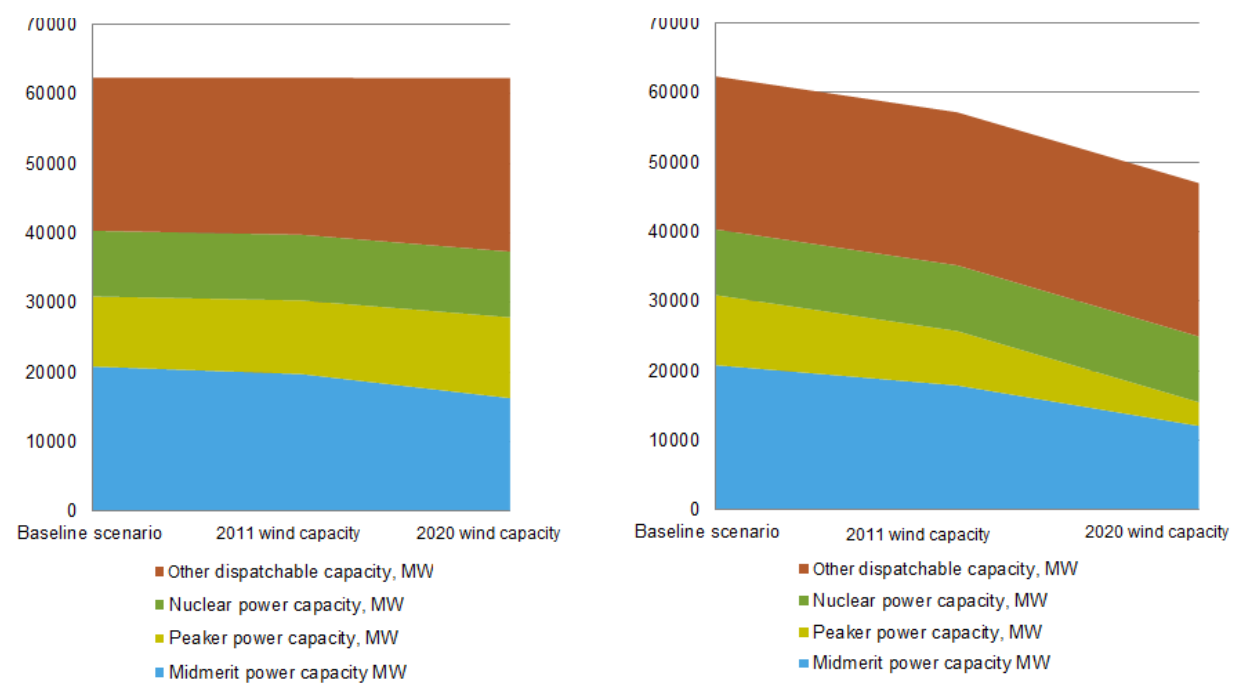

Figure 4. Capacities with constrained nuclear power

Next in Table 4 we present the impacts of different scenarios to production costs and profits. According to our assumptions only constrained (or intermittent) technologies can be able to make profits since the model assumes that midmerit and peaker technologies are optimized under zero profit condition. 
Table 4. Production costs and profits under constrained nuclear power

\begin{tabular}{|c|c|c|c|c|c|c|c|}
\hline Scenario & $\begin{array}{c}\text { Total } \\
\text { production } \\
\text { costs million } \\
€ \text { (with wind } \\
\text { in brackets) }\end{array}$ & $\begin{array}{l}\text { Costs } € / \mathrm{MWh} \\
\text { (with wind in } \\
\text { brackets) }\end{array}$ & $\begin{array}{c}\text { Profits } \\
\text { million } €, \\
\text { hydro } \\
\text { power }\end{array}$ & $\begin{array}{c}\text { Profits, } \\
\text { million } €, \\
\text { nuclear } \\
\text { power }\end{array}$ & $\begin{array}{c}\text { Profits, } \\
\text { million } €, \\
\text { wind power }\end{array}$ & $\begin{array}{c}\text { total profits, } \\
\text { million } €\end{array}$ & $\begin{array}{l}\text { Total } \\
\text { profits } \\
€ / \text { Mwh }\end{array}$ \\
\hline $\begin{array}{c}\text { Baseline } \\
\text { scenario A }\end{array}$ & 17975.65 & 48.05 & 5937.80 & 539.48 & & 6477.24 & 17.31 \\
\hline $\begin{array}{c}\text { Scenario } \\
\text { A1:1 }\end{array}$ & $\begin{array}{c}17082.81 \\
(17807.13)\end{array}$ & $47.45(47.54)$ & 5732.73 & 437.96 & 137.45 & 6308.14 & 16.84 \\
\hline $\begin{array}{c}\text { Scenario } \\
\text { A2:1 }\end{array}$ & $\begin{array}{c}17204.73 \\
(17929.05)\end{array}$ & $47.75(47.82)$ & 5489.59 & 276.26 & -124.59 & 5641.26 & 15.05 \\
\hline $\begin{array}{c}\text { Scenario } \\
\text { A3:1 }\end{array}$ & $\begin{array}{l}16810.05 \\
(17534.37\end{array}$ & $46.71(46.82)$ & 5882.31 & 513.44 & 478.19 & 6873.94 & 18.35 \\
\hline $\begin{array}{c}\text { Scenario } \\
\text { A1:2 }\end{array}$ & $\begin{array}{c}15357.32 \\
(17530.28)\end{array}$ & $46.23(46.62)$ & 5057.53 & 71.72 & 52.2 & 5181.54 & 13.78 \\
\hline $\begin{array}{c}\text { Scenario } \\
\text { A2:2 }\end{array}$ & $\begin{array}{c}15563.38 \\
(17736.34)\end{array}$ & $46.82(47.14)$ & 5000.20 & -178.51 & -690.38 & 4131.31 & 10.98 \\
\hline $\begin{array}{c}\text { Scenario } \\
\text { A3:2 }\end{array}$ & $\begin{array}{c}14491.77 \\
(16664.73) \\
\end{array}$ & $43.69(44.38)$ & 5689.59 & 424.50 & 1401.35 & 7515.49 & 20.16 \\
\hline
\end{tabular}

From the results we see that generation profile of intermittent power has clear impact on the production costs as well as on the profits. Interesting is that total production costs as well as production costs per MWh decrease in every scenario compared to the baseline scenario. One should note also that as the share of wind power increases the system costs slightly decrease. System costs are lowest when the intermittent generation is allocated according to "end" profile on the load duration curve.

The profitability of the producers is dependent, among other things, on the production profile and amount of intermittent generation. The highest profits are received by hydro power producers. Three observations to note are that wind power producers are making positive profits in four scenarios (without any support mechanism), that nuclear power producers are making negative profits under one scenario and that profits of dispatchable technology decreases as the amount of wind capacity increases. Total profits are highest when the intermittent generation is located according to "end" profile on the load duration curve (scenario A3) and it is increasing with the level of wind power generation. Total profits per MWh are clearly highest under scenario A3:2 i.e. when the amount of wind capacity is tripled from the level of 2011 and production profile is allocated according to "end" profile on the load duration curve.

From Table 5 we see that total emissions $\left(t / \mathrm{CO}_{2}\right)$ are decreasing clearly as the share of intermittent generation increases. Interesting is that opposite to the results related to capacity, costs and profits, emissions are not very sensitive to the production profile of intermittent generation. They seem to, however, increase somewhat if the intermittent generation is located more on peak demand hours (scenarios A3). This is because now the intermittent generation replaces more heavily peaker power production than midmerit production which has higher emissions per produced MWh. Midmerit power is assumed to use coal and peat, whereas peaker power is using oil and gas as a fuel. We have used the following fuel based emission multipliers $\left(\mathrm{tCO}_{2} / \mathrm{MWh}\right)$ in calculations (Note 10): coal (0.341), peat (0.382), gas (0.202) and oil (0.267).

Table 5. Emissions (constrained nuclear power)

\begin{tabular}{ccccc}
\hline Scenario & $\begin{array}{c}\text { Emissions peaker } \\
\text { power, million } \mathrm{tCO}_{2}\end{array}$ & $\begin{array}{c}\text { Emissions midmerit } \\
\text { power, million } \mathrm{tCO}_{2}\end{array}$ & $\begin{array}{c}\text { Total emissions, } \\
\text { million } \mathrm{tCO}_{2}\end{array}$ & $\begin{array}{c}\text { Total emissions } \\
\mathrm{t} / \mathrm{MWh}\end{array}$ \\
\hline Baseline scenario A & 2.30 & 82.28 & 84.58 & 0.226 \\
Scenario A1:1 & 2.43 & 69.65 & 72.08 & 0.192 \\
Scenario A2:1 & 2.42 & 70.01 & 72.43 & 0.193 \\
Scenario A3:1 & 1.84 & 70.85 & 72.69 & 0.194 \\
Scenario A1:2 & 2.86 & 44.53 & 47.39 & 0.126 \\
Scenario A2:2 & 2.67 & 45.92 & 48.60 & 0.129 \\
Scenario A3:2 & 0.91 & 48.11 & 49.01 & 0.131 \\
\hline
\end{tabular}


We have analysed the sensitivity of model results to changes in shares of real-time price customers (parameter $\alpha$ ) and price elasticities of demand (parameter ). The model results related to total capacity and total costs are strengthened (i.e. total capacity and total costs both decrease more compared to the baseline) as the share of real-time price customers increases or demand becomes more prices elastic. The results related to emissions are not sensitive to changes in parameter values of $\alpha$ and .

\subsection{Unconstrained Nuclear Power}

Next we present our simulation results under the situation where the capacity of nuclear power is not constrained. The model is now simulated in such a way that nuclear power is built under the same zero profit condition as peaker and midmerit power capacities. From Table 6 we can see the impact of different scenarios to production, capacities and price. We see that in the baseline scenario where we assume that there is no intermittent generation the optimal capacity level of nuclear power is $17746 \mathrm{MW}$. After the introduction of intermittent generation the optimal level of nuclear power is decreasing. Notable is that intermittent generation is clearly replacing also nuclear power in each of the scenarios. The level of nuclear power is smallest under scenario B2:2 i.e. when intermittent production is at the triple level of 2011 and it is allocated according to "beginning" profile to the load duration curve. It is also almost as low under the scenario B1:2 which uses the 2011 production profile. This is a significant result since it indicates that if (and as) the amount of intermittent generation is increasing it should be taken into account when planning new nuclear power investments. According to our results it is possible that further investments in nuclear power are not economically efficient if done simultaneously with large intermittent investments.

From the results we also see that when nuclear power is not constrained the production profile of intermittent generation becomes even more important. The difference on total dispatchable capacity among "beginning" and "end" profile is significant. One further implication of unconstrained nuclear power is that now the flat rate is clearly lower in every scenario compared to the scenarios where nuclear power is constrained.

Table 6. Production, capacities and prices with unconstrained nuclear power (Note 11)

\begin{tabular}{|c|c|c|c|c|c|c|c|c|}
\hline Scenario & $\begin{array}{c}\text { Total } \\
\text { Annual } \\
\text { Energy } \\
\text { consumed } \\
\text { (TWh) }\end{array}$ & $\begin{array}{c}\text { Total } \\
\text { dispatchable } \\
\text { capacity, } \\
\text { MW }\end{array}$ & $\begin{array}{c}\text { Peaker } \\
\text { power } \\
\text { capacity, } \\
\text { MW }\end{array}$ & $\begin{array}{l}\text { Midmerit } \\
\text { power } \\
\text { capacity } \\
\text { MW }\end{array}$ & $\begin{array}{l}\text { Nuclear } \\
\text { power } \\
\text { capacity }\end{array}$ & $\begin{array}{l}\text { Flat rate } \\
€ / \mathrm{MWh}\end{array}$ & $\begin{array}{c}\text { peak } \\
\text { price } \\
€ / \mathrm{MWh}\end{array}$ & $\begin{array}{c}\text { hours at } \\
\text { peak } \\
\text { quantity } \\
\text { (at } \\
8760)\end{array}$ \\
\hline $\begin{array}{c}\text { Baseline } \\
\text { Scenario B }\end{array}$ & 378.26 & 62745 & 10158 & 10108 & 17746 & 55.23 & 3137.02 & 87 \\
\hline $\begin{array}{c}\text { Scenario } \\
\text { B1:1 }\end{array}$ & 378.22 & 61153 & 10580 & 9857 & 16151 & 55.45 & 4841.70 & 83 \\
\hline $\begin{array}{c}\text { Scenario } \\
\text { B2:1 }\end{array}$ & 377.95 & 62638 & 10655 & 10797 & 15843 & 56.22 & 3248.20 & 87 \\
\hline $\begin{array}{c}\text { Scenario } \\
\text { B3:1 }\end{array}$ & 378.49 & 57551 & 7877 & 8513 & 16697 & 54.37 & 2316.67 & 99 \\
\hline $\begin{array}{c}\text { Scenario } \\
\text { B } 1: 2\end{array}$ & 378.10 & 58885 & 12111 & 9360 & 12849 & 56.26 & 5267.55 & 79 \\
\hline $\begin{array}{c}\text { Scenario } \\
\text { B2:2 }\end{array}$ & 377.43 & 62419 & 11653 & 12165 & 12034 & 58.45 & 3451.47 & 82 \\
\hline $\begin{array}{c}\text { Scenario } \\
\text { B3:2 }\end{array}$ & 379.04 & 47294 & 3438 & 5328 & 14597 & 52.45 & 1187.29 & 99 \\
\hline
\end{tabular}

From Figures 5a, 5b and 5c we see the impacts of different scenarios to the capacity mixture and total dispatchable capacity. If the intermittent production is allocated according to "beginning" profile on the load duration curve (scenarios B2) the total dispatchable capacity does not change almost at all. As the amount of intermittent generation increases it replaces only nuclear power capacity and actually the amount of peaker and midmerit capacities increase. This indicates possibilities for higher costs and emissions. The very opposite is true if the intermittent generation is located according to "end" profile (scenarios B3). Now, it replaces heavily both peaker and midmerit capacity and also decreases strongly the total amount of dispatchable generation. 

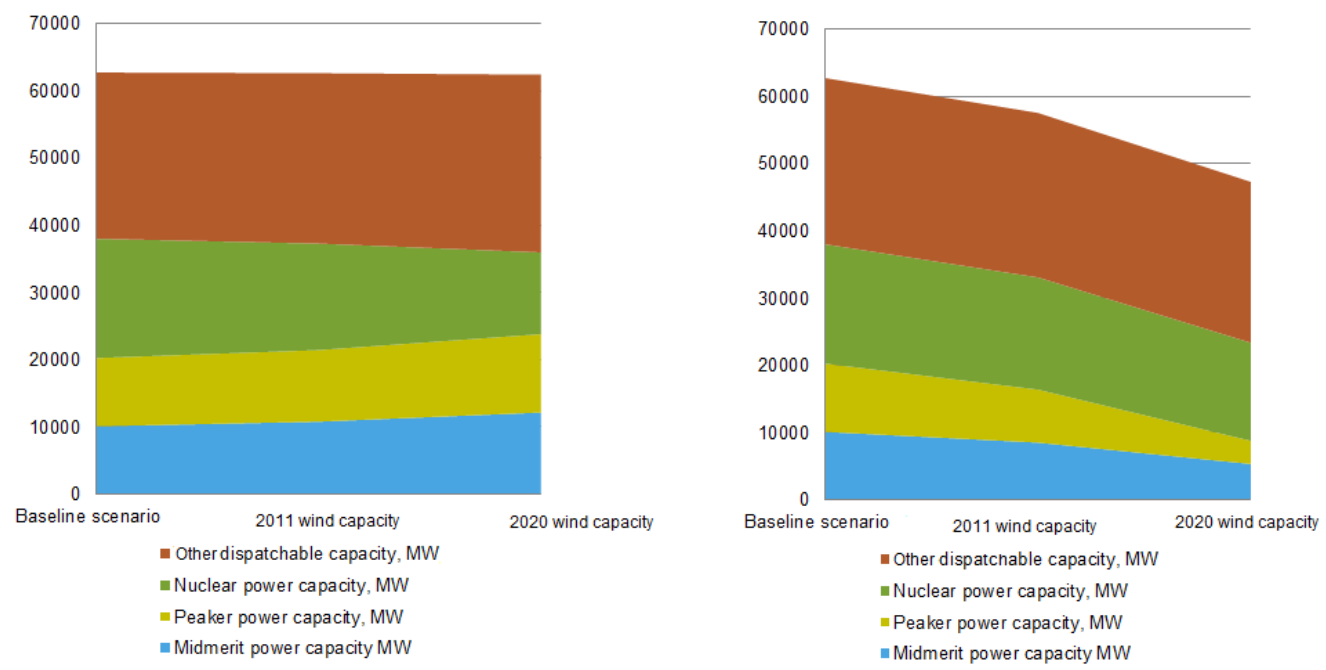

Figure 5. Capacities with unconstrained nuclear power

In Table 7 we present the results related to system costs and profits under the assumption of unconstrained nuclear power. Total production costs are decreased under every scenario compared to the scenarios when nuclear power is constrained. The same is true for the production costs per MWh. The costs are lowest under the scenario B3:2 i.e. when the amount of wind capacity is tripled and the production is located according to "end" profile on the load duration curve. Releasing the assumption of constrained nuclear power has a clear impact to the profits of the industry. Now, as assumed, the nuclear power is making zero profits. The profits of hydro power are reduced and consequently also the total profits are reduced. Under the "end" profile scenarios wind power is able to make positive profits, otherwise its profits are negative.

Table 7. Production costs and profits with unconstrained nuclear power

\begin{tabular}{cccccccc}
\hline Scenario & $\begin{array}{c}\text { Total } \\
\text { production } \\
\text { costs million } \\
€ \text { (with wind } \\
\text { in brackets) }\end{array}$ & $\begin{array}{c}\text { Costs } € / \text { MWh } \\
\text { (with wind in } \\
\text { brackets) }\end{array}$ & $\begin{array}{c}\text { Profits } \\
\text { million } €, \\
\text { hydro } \\
\text { power, }\end{array}$ & $\begin{array}{c}\text { Profits, } \\
\text { million } €, \\
\text { nuclear } \\
\text { power }\end{array}$ & $\begin{array}{c}\text { Profits, } \\
\text { million } €, \\
\text { wind } \\
\text { power }\end{array}$ & $\begin{array}{c}\text { total } \\
\text { profits, } \\
\text { million } €\end{array}$ & $\begin{array}{c}\text { Total } \\
\text { profits } \\
€ / \text { Mwh }\end{array}$ \\
\hline $\begin{array}{c}\text { Baseline } \\
\text { Scenario B } \\
\text { Scenario } \\
\text { B1:1 }\end{array}$ & $\begin{array}{c}16508.82 \\
15814.51\end{array}$ & 43.65 & 4161.50 & 0 & 0 & 4161.50 & 11.00 \\
$\begin{array}{c}\text { Scenario } \\
\text { B2:1 }\end{array}$ & $\begin{array}{c}16538.83) \\
15925.65\end{array}$ & $43.39(43.73)$ & 4124.72 & 0 & -13.84 & 4111.01 & 10.87 \\
$\begin{array}{c}\text { Scenario } \\
\text { B3:1 }\end{array}$ & $\begin{array}{c}15484.97) \\
(16210.19)\end{array}$ & $42.56(42.83)$ & 4102.86 & 0 & 386.66 & 4489.71 & 11.86 \\
$\begin{array}{c}\text { Scenario } \\
\text { B1:2 }\end{array}$ & $\begin{array}{c}14466.02 \\
(16638.99)\end{array}$ & $43.27(44.01)$ & 4124.90 & 0 & -234.79 & 3890.31 & 10.29 \\
$\begin{array}{c}\text { Scenario } \\
\text { B2:2 }\end{array}$ & $\begin{array}{c}14756.32 \\
(16929.29)\end{array}$ & $44.23(44.85)$ & 4562.90 & 0 & -830.81 & 3732.11 & 9.89 \\
$\begin{array}{c}\text { Scenario } \\
\text { B3:2 }\end{array}$ & $\begin{array}{c}13443.73 \\
(15616.69)\end{array}$ & $40.10(41.20)$ & 3986.04 & 0 & 1139.11 & 5125.28 & 13.52 \\
\hline
\end{tabular}

In Table 8 we present the results related to emissions from different scenarios and assuming optimized nuclear capacity. We see that total emissions decrease significantly as the nuclear power is not constrained. Emissions per MWh are lowest under the scenario B3:2 i.e. when the level of intermittent capacity is tripled and the production is located according to "end" profile i.e. more on the peak demand hours. The result was expected as we noted the strong change in capacity mixture discussed above. 
Table 8. Emissions (unconstrained nuclear power)

\begin{tabular}{ccccc}
\hline Scenario & $\begin{array}{c}\text { Emissions peaker } \\
\text { power, million } \mathrm{tCO}_{2}\end{array}$ & $\begin{array}{c}\text { Emissions midmerit } \\
\text { power, million } \mathrm{tCO}_{2}\end{array}$ & $\begin{array}{c}\text { Total emissions, } \\
\text { million } \mathrm{tCO}_{2}\end{array}$ & $\begin{array}{c}\text { Total emissions } \\
\mathrm{t} / \mathrm{MWh}\end{array}$ \\
\hline Baseline scenario B & 2.31 & 23.47 & 25.78 & 0.068 \\
Scenario B1:1 & 2.44 & 22.66 & 25.11 & 0.066 \\
Scenario B2:1 & 2.43 & 25.17 & 27.60 & 0.073 \\
Scenario B3:1 & 1.85 & 19.83 & 21.68 & 0.057 \\
Scenario B1:2 & 2.87 & 21.37 & 24.24 & 0.064 \\
Scenario B2:2 & 2.68 & 28.55 & 31.23 & 0.082 \\
Scenario B3:2 & 0.91 & 12.56 & 13.47 & 0.036 \\
\hline
\end{tabular}

Similarly as with respect to results related to constrained nuclear power scenarios we have analysed the sensitivity of model results also here. The results related to total capacity and total costs are also in this case strengthened as the share of real-time price customers increases or demand becomes more prices elastic. Again the results related to emissions are not sensitive to changes in parameter values.

\section{Conclusions}

We have utilized a long-run oriented simulation model in order to analyze the economic value of intermittent electricity generation in the Nordic power markets. We have simulated the model under different assumptions about the production profile of intermittent generation, about the amount of intermittent generation and about the level of nuclear power. First we assume that nuclear is constrained to the year 2011 level but later we release this assumption and nuclear power is built up to the point where it receives zero profits. Our simulations show that generation profile of intermittent power has clear impacts on the capacity structure, production costs as well as on the profits.

If higher amount of intermittent generation occurs at lower demand hours it replaces midmerit technology, but total dispatchable capacity changes only slightly. This is because only very little wind is allocated to the peak demand hours which is the main determinants of the total required capacity. The reverse is true if wind is allocated more heavily to the end of the load duration curve. In that case total dispatchable capacity decreases substantially. Because wind is now located more on peak demand hours it replaces a significant amount of peak capacity but has only little impact on the amount of midmerit capacity. The changes in the capacity mixture indicate that the wind profile might have significant impact on the system costs and also to the emissions. Interesting is that total production costs as well as production costs per MWh decrease in every scenario with intermittent generation compared to the baseline scenario when nuclear power is constrained. It is often argued that the integration of renewable energy decreases the cost efficiency of the power industry. According to our results this seems not to be the case. System costs are lowest when the intermittent generations is allocated according to the "end" profile i.e. more on the peak demand hours. Notable is that profits of dispatchable technologies decrease as the amount of wind capacity increases regardless of the production profile of intermittent generation. Production profile of intermittent generation has, however, significant effect on the profitability of wind generators and if the intermittent generation is located according to the "end" profile wind producers make clear profits. Consequently, even though the profits of dispatchable generators have decreased, total profits are highest when the level of wind capacity is tripled and it is allocated according to the "end" profile to the load duration curve.

Total emissions $\left(\mathrm{t} / \mathrm{CO}_{2}\right)$ are decreasing clearly as the share of intermittent generation increases. Interesting is that opposite to the results related to capacity, costs and profits, emissions are not very sensitive to the production profile of intermittent generation in the case when nuclear power is constrained. Emissions seem to, however, increase somewhat if the intermittent generation is located more on peak demand hours. This is because now the intermittent generation replaces more heavily peaker power production than midmerit production which has higher emissions per produced MWh.

When we look at the results when nuclear power is not constrained the production profile of intermittent generation becomes even more important. The difference on total dispatchable capacity among the "beginning" and the "end" profile is significant. Notable is that intermittent generation is clearly replacing also nuclear power in each of the scenarios. The level of nuclear power is smallest under scenario when intermittent production is at the triple level of 2011 and it is allocated according to "beginning" profile on the load duration curve. It is also 
almost at low under the scenario which uses the 2011 production profile. This is a significant result since it indicates that if (and as) the amount of intermittent generation is increasing it should be taken into account when planning new nuclear power investments. According to our results it is possible that further investments in nuclear power are not economically efficient if done simultaneously with large intermittent investments.

One further implication of unconstrained nuclear power is that now the flat rate is clearly lower in every scenario compared to the scenarios where nuclear power is constrained. We see also that total emissions decrease significantly as the capacity of nuclear power is not constrained but optimized. Contrary to the constrained nuclear power case, also the production profile of intermittent generation has clear impact on the emissions. Emissions are clearly lowest when the intermittent generation is allocated according to the "end" profile.

\section{Acknowledgements}

We thank the participants of the following conferences for their valuable comments: the $11^{\text {th }}$ International Industrial Organization Conference (Boston, 2013), the International Energy Workshop (Paris, 2013), the 20 ${ }^{\text {th }}$ Annual Conference of European Association of Environmental and Resource Economists (Toulouse, 2013) and the Annual Conference of the Finnish Economic Society (Mariehamn, 2013). We thank Yrjö Jahnsson foundation for funding.

\section{References}

Borenstein, S. (2005). The Long-Run Efficiency of Real-Time Electricity Pricing. The Energy Journal, 26(3), 93-116. http://dx.doi.org/10.5547/ISSN0195-6574-EJ-Vol26-No3-5

Borenstein, S. (2007). Wealth Transfers from Implementing Real-Time-Retail Electricity Pricing. The Energy Journal, 28(2), 131-49. http://dx.doi.org/10.5547/ISSN0195-6574-EJ-Vol28-No2-6

Borenstein, S., \& Holland, S. (2005). On the Efficiency of Competitive Electricity Markets with Time-Invariant Retail Prices. RAND Journal of Economics, 36(3), 469-93.

Bye, T., \& Hansen, P. V. (2008). How do spot prices affect aggregate electricity demand? Discussion Paper 527, Research Department of Statistics Norway.

Chalkiadakis, G., Robu, V., Kota, R., Rogers, A., \& Jennings, N. R. (2011). Cooperatives of distributed resources for efficient virtual power plants. Proc. of 10th Int. Conf. on Autonomous Agents and Multiagent Systems Innovative Applications Track (AAMAS 2011), Tuner, Yolum, Sonenberg and Stone (Eds.).

Chen, J., Mount, T. D., Thorp, J. S., \& Thomas, R. J. (2005). Location based scheduling and pricing for energy and reserves: a responsive reserve market proposal. Decision Support Systems, 40, 563-577. http://dx.doi.org/10.1016/j.dss.2004.09.006

Damsgaard, N. (2003). Deregulation and regulation of electricity markets (Unpublished doctoral dissertation). Stockholm School of Economics, Sweden.

EC (European Commission). (2007). EnergyPortal. Retrieved November 11, 2012, from ww.energy.eu/publications

Eurelectric. (2012). Power Statistics \& Trends, 2012 Edition. Retrieved February 30, 2013, from www.eurelectric.org/powerstats2012

Green, R., \& Vasilakos, N. (2010). Market behavior with large amounts of intermittent generation. Energy Policy, 38, 3211-3220. http://dx.doi.org/10.1016/j.enpol.2009.07.038.

Johnsen, T. A. (2001). Demand, generation and price in the Norwegian market for electric power. Energy Economics, 23, 227-251. http://dx.doi.org/10.1016/S0140-9883(00)00052-9

Joskow, P. L. (2011). Comparing the costs of intermittent and dispatchable electricity generating technologies. EUI Working Papers RSCAS 2011/45.

Joskow, P. L. (2012). Creating a Smarter U.S. Electricity Grid. Journal of Economic Perspectives, 26, 29-48. http://dx.doi.org/10.1257/jep.26.1.29.

Kopsakangas-Savolainen, M., \& Svento R. (2013). Promotion of market access for renewable energy in the Nordic Power markets. Environmental and Resource Economics, 54, 549-569. http://dx.doi.org/10.1007/s10640-012-9605-z

Kopsakangas-Savolainen, M., \& Svento, R. (2012a). Modern Energy Markets; Real-Time Pricing, Renewable Resources and Efficient Distribution. Springer UK, London.

Kopsakangas-Savolainen, M., \& Svento, R. (2012b). Real-Time Pricing in the Nordic Power Markets. Energy 
Economics, 34(4), 1131-1142. http://dx.doi.org/10.1016/j.eneco.2011.10.006

Lamont, A. D. (2008). Assessing the long-term system value of intermittent electric generation technologies. Energy Economics, 30, 1208-1231. http://dx.doi.org/10.1016/j.eneco.2007.02.007

Li, N., Chen, L. \& Low, S. H. (2011). Optimal Demand Response Based on Utility Maximizing in Power Networks. IEEE 978-1-4577-1002-5/11. Retrieved from http://dx.doi.org/10.1109/PES.2011.6039082

Mount, T., Maneevitjit, S., Lamadrid, A. J., Zimmerman, R. D., Thomas, R. J. (2011). The hidden system costs of wind generation in a deregulated electricity market. WP 2011-01, Cornell University, New York.

Saad, W., Han Z., Poo,r H V., \& Basar, T. (2012). Game-Theoretic Methods for the Smart Grid. An overview of microgrid systems, demand-side management, and communications. IEEE Signal Processing Magazine 2. http://dx.doi.org/10.1109/MSP.2012.2186410

Saad, W., Han, Z., Poor, H. V. (2011). Coalitional Game Theory for Cooperative Micro-Grid Distribution Networks. IEEE 978-1-61284-955-3/11. Retrieved from http://dx.doi.org/10.1109/iccw.2011.5963577

Tarjanne, R., \& Kivistö, A. (2008). Comparison of electricity generation costs, Research report EN A-56 Lappeenranta University of Technology, Finland. Retrieved from http://urn.fi/URN:ISBN:978-952-214-588-8

Vainio, T. (2011). Sähkön tuotantokustannusvertailu, Työpaperit, Tiede+teknologia, Aalto University, Helsinki. Retrieved from http://lib.tkk.fi/TIEDE_TEKNOLOGIA/2011/isbn9789526041353.pdf

\section{Notes}

Note 1. We use wind as a representative technology of intermittent generations because due to weather conditions the role of solar power is, at least at the moment, very modest in the Nordic Power Markets.

Note 2. Estonia joined the common Nordic Power market in 2010. Because, however, hourly consumption data from 2011 (which we use in simulations) is not available from Estonia, it is excluded from this study.

Note 3. For the model sensitivity of the share of real-time price customers and price elasticity of demand see Kopsakangas-Savolainen and Svento (2012b).

Note 4. Several studies support the view of inelastic electricity demand in Nordic countries (see e.g. Johnsen (2001), Damsgaard (2003) and Bye and Hansen (2008)). In most of the studies estimates for elasticity values varies from $-0,35$ to $-0,79$.

Note 5 . We begin with peaker technology because if it used at all it will be used in the highest demand hour.

Note 6. Even though in final equilibrium baseload capacity refers to the nuclear power, for modeling reasons we first, assume that the baseload constraint is equal to the capacity of nuclear power and hydro power together.

Note 7. By utilizing hydro power this way, the results from simulations can be generalized also to such markets where production technologies do not include hydro power.

Note 8. The aggregate wind power capacity of Finland, Sweden, Denmark and Norway was 6553 MW in 2011 and the target is to reach $25600 \mathrm{MW}$ by the year 2020. We have excluded the wind capacity of Norway (441 MW) because of missing hourly production data and because at least Finland is behind the targeted investment schedule, we use only tripled level (18336 MW) of 2011 capacity instead of level $25600 \mathrm{MW}$.

Note 9. Total dispatchable capacity includes only the average amount of hydropower capacity in use. This assumption does not change the results because we assume that hydropower capacity and its amount of production are constrained to the level of year 2011.

Note 10. Note that these multipliers have to be used to the amount of primary energy used in production.

Note 11. We make similar assumption on hydro power as in scenarios with constrained nuclear power.

\section{Copyrights}

Copyright for this article is retained by the author(s), with first publication rights granted to the journal.

This is an open-access article distributed under the terms and conditions of the Creative Commons Attribution license (http://creativecommons.org/licenses/by/3.0/). 